\title{
Left Intercostal Approach for Laparoscopic Isolated Total Caudate Lobectomy (with Video)
}

\author{
Kenei Furukawa ${ }^{1} \cdot$ Shinji Onda ${ }^{1} \cdot$ Toru Ikegami $^{1}$
}

Received: 24 June 2021 / Accepted: 17 August 2021 / Published online: 20 September 2021

(c) The Society for Surgery of the Alimentary Tract 2021

\begin{abstract}
Background Laparoscopic total caudate lobectomy remains a challenging procedure because of its deep location (Xu et al., Surg Endosc. 35:1138-47, 2021). Placement of intercostal ports can overcome the barriers of the ribcage for laparoscopic access (Hayashi et al., PLoS One.15:e0234919, 2020). We herein present a novel technique in which a left intercostal port was used as the main working port during laparoscopic caudate lobectomy.

Methods An 84-year-old man with a 1-cm intrahepatic cholangiocarcinoma located in segment 1 (S1) was referred to our hospital. We planned laparoscopic isolated caudate lobectomy using a left intercostal port as the main working port. The patient was placed in the supine position. A $12-\mathrm{mm}$ left intercostal port with a balloon was introduced in the seventh intercostal space as the main working port. After Arantius' ligament was divided, the left Glissonean pedicle of S1 (G1) was divided using an endo-stapling device. The surgeon moved to the right side of the patient and divided the right G1, followed by transection to the inferior right hepatic vein. Again, the surgeon moved to the left side, and the left intercostal port was used for mobilization of the Spiegel lobe and parenchymal resection using a cavitron ultrasonic surgical aspirator, exposing the root of the left and middle main hepatic veins for completion of total caudate lobectomy.

Results The operative time was $264 \mathrm{~min}$ and blood loss was $400 \mathrm{~mL}$. The patient was discharged on a postoperative day 9 without complications.

Conclusions A laparoscopic approach to the caudate lobe using a left intercostal port is a new and ideal technique providing effective manipulation.
\end{abstract}

Keywords Laparoscopic hepatectomy $\cdot$ Caudate lobectomy $\cdot$ Intercostal port

\section{Abbreviations}

S1 Segment 1

G1 Glissonean pedicle of S1

Supplementary Information The online version contains supplementary material available at https://doi.org/10.1007/s11605-021-05128-5.

Acknowledgements The authors thank Angela Morben, DVM, ELS, from Edanz (https://jp.edanz.com/ac), for editing a draft of this manuscript.

Funding This work was supported by a JSPS KAKENHI grant (JP21K08718) and by a research grant from the Uehara Memorial Foundation (to T.I.).

Kenei Furukawa

k-furukawa@jikei.ac.jp

1 Division of Hepatobiliary and Pancreas Surgery, Department of Surgery, The Jikei University School of Medicine, 3-25-8, Nishi-Shinbashi, Minato-ku, Tokyo 105-8461, Japan

\section{Declarations}

Competing Interests The authors declare no competing interests.

\section{References}

1. Xu G, Tong J, Ji J, Wang H, Wu X, Jin B, Xu H, Lu X, Sang X, Mao Y, Du S, Hong Z. Laparoscopic caudate lobectomy: a multicenter, propensity score-matched report of safety, feasibility, and early outcomes. Surg Endosc. 2021;35:1138-47.

2. Hayashi H, Yamashita YI, Okabe H, Imai K, Higashi T, Yamamura K, Chikamoto A, Beppu T, Takamori H, Baba H. Varied application of intercostal trans-diaphragmatic ports for laparoscopic hepatectomy. PLoS One. 2020;15:e0234919.

Publisher's Note Springer Nature remains neutral with regard to jurisdictional claims in published maps and institutional affiliations. 